\title{
Brand Importance across Product Categories in the Czech Republic, the Slovak Republic and the Russian Federation
}

DOI: 10.12776/QIP.V20I2.689

\author{
Radek Tahal, Tomáš Formánek
}

Received 1 March 2016, Revised 17 June 2016, Accepted 8 August 2016

\begin{abstract}
Purpose: Customer loyalty is an important and complex aspect of the market environment. This study aims at analysing the significance attached by different customer groups to brands in particular product categories within the Fast Moving Consumer Goods sector and to enhance existing knowledge in this field.

Methodology/Approach: This study is based on primary data gathered through a consumer survey that was consistently carried out in the Czech Republic, the Slovak Republic and the Russian Federation during November 2015. Different quantitative and statistical analysis methods and tests are applied. Logistic regression and average partial effect estimation form the main base for conclusions presented.
\end{abstract}

Findings: This study focuses on two key research topics: First, we describe how much does a perceived brand importance differ across various product categories. Second, we identify and quantify the influence of important socio-demographic and lifestyle factors that affect the potential for brand loyalty across different product categories. Main findings are highlighted and interpreted.

Research Limitation/implication: For the three countries involved, this study describes the topical situation at the time of the survey. In the coming years, repeated surveys might identify changes and trends in customer behaviour.

Originality/Value of paper: This paper is based on primary data, consistently gathered across three countries. By means of advanced statistical analysis, the authors provide comprehensive quantitative output that may be used for immediate marketing purposes and for further scientific research.

Category: Research paper

Keywords: product categories; brand; loyalty; customer; FMCG 


\section{INTRODUCTION}

One of the basic marketing activities may be described as efforts made by one participant - typically a corporate entity - to attract consumers' ${ }^{\prime}$ attention towards offered products and services. Building customer relations is not a one-off operation, but a continuous process with many follow-up steps and repeated activities. In order to properly analyse customer relations, or even loyalty (which is a higher degree of connection with customers, based on their positive attitudes towards a brand), it may be useful to mention two elementary factors that marketers have to deal with.

The first step is to trigger customers' motivation for buying. The so-called USP (Unique Selling Proposition) is a parameter, or a complex of parameters, presented by a seller and perceived by customers as the significant positive differentiator from any competing offers. The other, equally important step is to retain customers' interest, i.e. to achieve and secure repeated purchases that are based on sufficient and sustained differentiation towards competitors. Relevant research papers indicate existing relationships between brand consciousness, brand preference, brand sensitivity, and brand importance aspects, yet significant knowledge gaps exist in this field (e.g. Zablah, Brown and Donthu, 2010).

The question of loyalty is especially important in the Fast Moving Consumer Goods (FMCG) sector, often labelled as the non-durable goods. Customers' retention in this sector is very important and it directly influences corporate profitability (e.g. Buckinx and Van den Poel, 2005). The purchasing cycle in this sector is considerably short and the influence of externalities and macrofactors is low. Managers of market-oriented companies are well aware of the high value of customers who make repeated purchases. Customers' long-term positive attitudes towards a brand are called customer loyalty. This loyalty can be influenced by various factors. An important part is played by individual customer's emotions and social environment. For example, when using the products or services, customers may want to relate themselves to a certain reference group, either associatively (a group that the customer wants to be included in), or dissociatively (a group that the customer wants to differ from).

Strengthening of customer loyalty is generally motivated by an expected increase in corporate profits, both short-term and long-term. Customer loyalty towards a particular brand is frequently stimulated by specific marketing tools, such as loyalty programs. Present-day loyalty programs accentuate continuous, uninterrupted relations with customers. Long-term connections foster relational dynamics and enhance the positive impact of trust, commitment, and involvement in use (Grayson and Ambler, 1999, p.132).

This paper deals with customer loyalty towards various product categories within the FMCG sector. Our approach is based on the assumption that some product categories may be characterized by a stronger tendency to create loyalty bonds, as opposed to other product categories with weaker bonds. So far, consumer perceptions and preferences with respect to brand categories have received little 
attention in the academic research literature (Ghose and Lowengart, 2013, p.4). Compared to preceding studies on this topic, we provide additional insight by extending the focus from our home country (the Czech Republic) to the Slovak Republic and the Russian Federation as well. Our approach secures consistency in data gathering and subsequent quantitative analyses - a crucial factor for presenting and comparing results across different states.

This paper is organized as follows: Chapter 2 contains a brief literature review that is oriented towards brand importance aspect along diverse product categories. In chapter 3, we formally postulate our main research questions. Chapter 4 provides information on the methodology applied and specific data handling issues. Chapter 5 presents the interpretation of the research results and related statistical tests. The last section concludes our paper, along with the list of references.

\section{PRODUCT CATEGORIES AND BRAND IMPORTANCE IN LITERATURE}

Customer loyalty and its many aspects make for some of the most important present-day tools of marketing. At the same time, there is a long marketing history, dating back to 1940s. This may be observed from the following quotation: When loyalty is considered in relation to specific brands, a fairly high degree of loyalty exists (Guest, 1944). The loyalty concept was refined and developed in 1950s, with focus on the behavioural aspects of loyalty (e.g. Cunningham, 1956). Later on, the loyalty concept appears repeatedly in literature. Among others, Bennet (2001) describes attitudinal brand loyalty and its strong impact on the behavioural brand loyalty. In the middle of the 20th century, loyalty was approached as a unidimensional concept, defined by the measurement paradigm adopted by the researcher. Nowadays, loyalty is perceived as a multi-dimensional rendition by the vast majority of marketing practitioners and researchers (see e.g. Rundle-Thiele, 2005).

Customer loyalty is an inherently sensitive phenomenon. Many factors exist that may influence customer behaviour and they may be summarized using various types of definitions. Loyalty can be described as a deeply held commitment to rebuy preferred products or patronize a service consistently in the future (Oliver, 1999, p.34). Also, it is very firmly linked to satisfaction. For example, Sambandam and Lord (1995) present research results that indicate less concern with seeking alternatives in customers who have found a service they enjoy and continue to use. Customer loyalty is the result of mental processes taking place in the customers' minds. In literature, loyalty formation is often described as a multistep process. For example, Oliver (1999, p.35) describes loyalty as a threephase process: In the first phase, customers prefer a brand to its alternatives. In the second phase, the liking of the brand as based on satisfying usage occurrences has developed, and the third phase is defined by a specific level of commitment to repurchase. Similar approaches may be identified in research 
papers published by significant and reputable companies. For example, the SAS company frequently points to the fact that customer satisfaction is strongly interrelated with brand affinity (SAS, 2014).

Marketing professionals often emphasize that loyalty is closely connected to trust. Trust is sometimes described as customer's willingness to face the risk of a new purchase, based on a previous positive experience (e.g. Lau and Lee, 1999). Thus, Business to Consumer (B2C) marketers rely on brands to build the desired relationships. Therefore, brands serve as an important link between producers (companies) and their customers.

Loyalty may also be described as a pyramid built up of several tiers. Repeated purchases make for the first step, but they do not necessarily indicate loyalty, as re-purchases may be induced by many factors, like geographical locality, absence of competitors etc. Customer satisfaction can be considered as the second step and loyalty is at the top of the pyramid reflecting the stages of brand attitude in customers' minds. Loyalty is intrinsically mirrored in customers' behaviour and it is therefore transmitted to their milieus (see e.g. García Gómez, Gutiérrez Arranz and Gutiérrez Cillán, 2006). Quantitative preference analysis approach may be used to identify significant attributes that consumers use to develop their specific attitudes towards particular brand categories. Naturally, diverse drivers could be salient for different brand categories (Ghose, Lowengart 2013, p.7.)

Brand loyalty can be studied from many perspectives. Some analyses emphasize the role of loyalty programs (see e.g. Meyer-Waarden, 2007), other focus on situational loyalty that is related to events such as annual purchases bound with specific occasions (see e.g. McMullan and Gilmore, 2008). All such loyaltyfocused studies should be focused on brands, because customer loyalty is tied to particular products, product groups or services. Some product categories may be characterized by their capacity to induce customer loyalty towards a given brand easily (see e.g. Oliver, 1999) while other categories may lack this feature. The general importance of brands is based on the fact that brands have a potential to elicit positive emotional responses in the average customer, as a result of being used. (see e.g. Chaudhuri and Holbrook, 2001). Both category and brand/product marketing activities may influence consumers into purchasing specific brands or products and to be loyal toward them (Huy and Olsen, 2013, p.594).

\section{RESEARCH FOCUS}

All the above mentioned aspects of loyalty considered, our research focuses on contributing to the existing knowledge by providing stratified quantitative information about the loyalty potential of brands in selected product categories for different sociodemographic groups of consumers and across three selected countries/economies. The potential magnitude of the power that attracts customers to brands is important, as marketers need to know what amount of a customers' purchases come their way in terms of actual and potential sales (Garland and Varey, 2006). From the marketers' perspective, it is crucial to know 
(i.e. to have access to relevant estimates) whether there are any gender differences in brand loyalty, whether the potential for brand loyalty in a given product category varies along standard sociodemographic factors (nationality, age, education) and if factors such as lifestyle preferences play any significant role.

Given the above mentioned facts, we use product categories as the basic unit of analysis in this study. It is common in marketing that a virtual funnel is used for classification of brands and that brands are clustered into generally defined FMCG categories or sectors. Whenever quantitative or Likert-type scales are used to measure the magnitude of loyalty (potential loyalty), it is essential to examine how customers classify product categories according to the loyalty potential they feel towards brands in different categories. As the current-market environment is often characterized by strong competition, it is very important for companies to build a stable customer portfolio for each specific target segment. For retailers, loyalty programs make one of the most commonly used marketing tools. In order to make such loyalty programs effective, it is necessary to take into account many different parameters of the program, which may vary significantly across product categories.

Customer loyalty is closely related to brands. Brand attitudes are an important starting point in building a conceptual model of consumer-brand relationships. (Fullerton, 2005, p.100). Frequent terms used in connection with brand loyalty, encompassing trust and repurchase intention are "brand commitment", "brand trust", or "brand community" (Hur, Ahn and Kim, 2011). Target groups can be described in terms of various suitable lifestyle factors, which may prove useful for marketing purposes. This way, companies can describe their typical customers in a broader context. Therefore, standard customer profile characteristics consisting of sociodemographic data (age, living place or education) can be augmented by "soft information" such as purchasing habits, work preferences, cultural background, free time activities and attitudes toward matters such as nature protection, etc. Chung and Hsu (2012, p.304) make a similar statement, by pointing out the advantages of quantified lifestyle factor information for tasks such as market strategy development or market segmentation.

The authors of this paper carried out consistent research (in terms of data gathering and subsequent analyses) in the Czech Republic, the Slovak Republic and in the Russian Federation. Our research aims to find out the degree of importance ascribed to brands in particular product categories by customers in the three countries. The respondents were asked to anonymously provide their socio-demographic data, lifestyle preferences, consumer behaviour information and attitudes towards finances and savings. For this purpose, the respondents were presented with almost thirty statements for which they were asked to indicate the intensity of agreement or disagreement with the statement considered. Statements such as "I do sports/fitness activities", "I follow the news and keep myself informed about current events", "I am active in my job, I am 
assertive and ambitious", "I like to buy a nice thing, even if I have to take a loan" may serve as examples.

Our target is twofold: it consists not only in finding out the strength of the consumer bond to the brands in particular product category, but we also aim to find differences in the consumers' characteristic features across product categories. Such analysis may significantly contribute to effective marketing communication and for improved targeting processes, i.e. finding suitable customer target groups and focusing money and efforts accordingly. In our paper, we use the surveyed primary data to answer two main questions:

Research question 1: In what product categories do customers attach importance to brands, and how much does the brand importance differ across product categories.

Research question 2: Which of the socio-demographic and lifestyle factors may significantly influence brand loyalty for different product categories, and what is the actual importance of each of these factors.

\section{RESEARCH METHODOLOGY}

For our analysis of consumers' brand loyalty across different product types, we use the following product categories: (a) Drugstore, (b) Master domestic appliances, (c) Small domestic appliances, (d) Electronics, (e) Hobby \& garden, (f) Toys, (g) Household equipment, (h) Clothing, (i) Shoes, (j) Food $\&$ beverages, (k) Restaurants. This classification reflects common retail and marketing practice, as products are often categorized for the purpose of retail analysis, planning, audit, etc. Also, such product classification is supported in literature (see e.g. Oliver, 1999).

Our research was performed using primary survey data for three selected countries: the Czech Republic (CR), the Slovak Republic (SR) and the Russian Federation (RF). Given practical data-gathering limitations and RF's inherent cultural \& economic diversity, only the Moscow Region and the Southern Federal Region were used for this research paper. A complex, stratified/quota sampling anonymized survey was performed during November 2015, gathering a sample consisting of 490 respondents from a population of retail consumers aged 15+. The stratified/quota sampling was based on gender, age segmentation and location of the respondents (the above mentioned limitations on domicile sampling apply to RF). The survey was focused on gathering respondents' sociodemographic data, answers to questions related to brand stance on different product categories, free-time and lifestyle preferences, self-positioning and attitudes toward various types of work and leisure activities. Different types of questions were used in the survey: quantitative (mostly interval-based), qualitative (Yes/No) and Likert scale (various degree spans are used). Both online and personal (paper-based) data collection methods were used. To avoid data handling errors, our questionnaires feature a fixed order of statements as three 
language mutations, on-line $\&$ paper-based data sources are combined into one dataset for subsequent analysis. The survey was performed by researchers at the University of Economics, Prague. The research team was led by university employees and teachers who coordinate and supervise the work of students specializing on marketing research. This study is part of a long-term project of systematic scientific surveys and analyses of customer loyalty (see Tahal and Stříteský, 2014 or Formánek and Tahal, 2016).

Empirical data analysis is based on logistic regression models and related tests, as this approach allows to control for stratified/quota sampling (see James et all., 2013). Also, for survey data-validation, the Wald-Wolfowitz "Runs" test (see Wackerly, Mendenhall and Scheaffer, 2008) was used to test the $\mathrm{H}_{0}$ of order of observations being attributable to chance against the $\mathrm{H}_{1}$ of potential survey mishandling.

All data gathered from individual survey questions were processed into qualitative (binary) indicators for subsequent evaluation and modelling. The transformation of answers to Yes/No questions is trivial and for the quantitative (interval-based) variables, we use binary indicators describing the interval where the respondent falls in (e.g. the variable Age_15_24 equals 1 for all respondents aged 15 to 24 and is zero otherwise). Answers to the Likert scale-based questions have a qualitative nature and belong to a class of ordered multinomial data. For example: for the dependent variables of our model (1), we use Likert scale to record respondents' positions on brand importance in different product categories (value " $1 "=$ brand in the product category is very important to me; ... ; value " 4 " = brand in the product category is totally unimportant to me). The fact that " 1 " is a better rating (brand importance perception is stronger) than " 2 " conveys useful information, but the rating has ordinal meaning only - we cannot say that the difference between " 1 " and " 3 " is twice as important as the difference between "3" and "4".

Generally speaking, Likert scale data allow for the application of ordered multinomial regression models. However, this rather complex approach (based on a concept of latent dependent variables) leads to estimated model coefficients that cannot be simply and unambiguously interpreted for the intermediate responses, i.e. for all responses but the best and worst Likert scale outcomes (for detailed discussion, see Wooldridge, 2010, p.665). Hence, considering both the nature of our survey data and our research focus, we record the Likert scale data as binary variables in a way that corresponds with our research focus and does not impair the interpretability of our results: For responders who attach considerable importance to brands in a particular product category (response " 1 " on the Likert scale), we record a "success" (our binary variable equals 1 for the $i$-th surveyed individual), while responses " 2 " to " 4 " on the Likert scale lead to zero-value observations of the binary variable (as the $i$-th surveyed individual attaches limited or no importance towards brands in a given product category).

In a rather similar manner, different lifestyle factor questions that respondents addressed using Likert scale choices were used to produce binary indicators - 
potential regressors for our models. The transformation of lifestyle data for use in quantitative models may be briefly described using a second example. For a statement "I like watching TV", respondents were asked to position themselves on a five degree Likert scale (" 1 " = this statement describes me very well, " 5 " = this statement does not describe me at all). Please note that the subjectively perceived importance to one's lifestyle is addressed here, rather than the actual watching time. Answers to this particular question were used to produce two binary variables: $L S_{-} T V_{-}$yes equals 1 for those who reported " 1 " on the Likert scale and zero otherwise, LS_tv_no equals 1 for those who dissociated themselves from the statement by answering " 5 " (and it equals zero otherwise). Using this approach, we are able to select all the cases where respondents have strong positions on a specific activity or lifestyle: e.g. going to cinema, reading books, doing sports, being a vegetarian, eating fast-food, etc. To finalize the TV example, we should note that all the answers "2" to "4" (not a very strong position on the topic) are combined into one category and may still be implicitly included in the analysis by forming a base (reference "attitude", i.e. respondent's position), necessary for interpretation of coefficients in the estimated regression models. Also, using the answers " 2 " to " 4 " as a basis has the advantage of decoupling the LS_TV_yes and LS_TV_no binaries: those are not linearly dependent (at least theoretically) and might be both used as regressors in the same regression equation.

Hence, we have transformed the survey material into a 490-row dataset containing 11 binary indicators describing whether respondents attribute high importance to brands in 11 different product categories. Also in the dataset, we have 68 potential explanatory variables, containing sociolo-demographic data, individual lifestyle preferences and other relevant information. In order to select a representative and consistent set of explanatory variables, we use a nonparametric random forest approach (see James et al., p.318-321) to evaluate the importance of explanatory variables. This computationally feasible approach (the random forest for each product category consisted of 5,000 trees in our case) produced a relevant set of regressors. This approach may be regarded as an acceptable approximation to the computationally implausible search for the optimum (best) model. In our case, the brute-force approach to model selection would require a total of $2^{68}$ possible regression model specifications to be estimated and evaluated for each of the 11 dependent variables (see James et al., 2013, p.205).

The information on regressor importance as gathered for all dependent variables was used to generate a consistent model specification encompassing a total of eleven socio-demographic and lifestyle (LS) explanatory variables: 


$$
\begin{aligned}
& y_{i}=\beta_{0}+\beta_{1} \text { Female }_{i}+\beta_{2} \text { Age_15_24 } i+\beta_{3} \text { Age_25_34 }{ }_{i} \\
& +\beta_{4} \text { Age_35_49 }{ }_{i}+\beta_{5} S V K_{i}+\beta_{6} R U S_{i}+\beta_{7} \text { LS_Paycard_yes }_{i} \\
& +\beta_{8} L S_{-} \text {tourist_yes }{ }_{i}+\beta_{9} L S_{-} \text {greenfing_yes }{ }_{i}+\beta_{10} L S_{-} T V_{-}{ }_{1} y e s_{i} \\
& +\beta_{11} \text { Earnings_low }_{i}+u_{i} \text {, }
\end{aligned}
$$

where $y_{i}$ is a binary dependent variable describing whether the $i$-th respondent regards brands in a chosen product category as highly important to him/her and $\beta_{j}$ are the regression parameters. Female $e_{i}$ is a binary explanatory variable distinguishing between female and male respondents, Age_15_24 $4_{i}$, Age_25_34 and $A g e_{-} 35_{-} 49_{i}$ are binary variables indicating the age category where the $i$-th respondent belongs to (for empirical reasons, age ranges 50-64 and 65+ were combined into a single reference category: age 50+). $S V K_{i}$ and $R U S_{i}$ variables describe the country of residence of respondents (the Czech Republic serves as the reference category). LS_Paycard_yes ${ }_{i}$ indicates whether the $i$-th respondent identifies himself/herself with actively using pay cards (credit and debit).

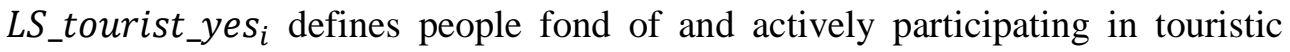
activities. Respondents keen of gardening (growing fruits and vegetables, lawn mowing, etc.) are discerned using $L S_{-}$greenfing_yes ${ }_{i}$. LS_TV_yes $S_{i}$ has been introduced above. Earnings_low $w_{i}$ marks the respondents belonging to the lowest-income category. Earnings-wise, respondents were divided into four groups based on household income - with consistency of categorization across the three countries in mind. Earnings_low $w_{i}=1$ for household income of up to 780 EUR (or equivalent in local currency) per month. Finally, $u_{i}$ is the potentially heteroscedastic random element of regression. Using matrix notation, the logistic function used for estimation of the parameters $\beta_{j}$ in (1) may be rewritten as

$$
P\left(y_{i}=1 \mid \boldsymbol{x}_{i}^{T}\right)=G\left(\boldsymbol{x}_{i}^{T} \boldsymbol{\beta}\right)=\exp \left(\boldsymbol{x}_{i}^{T} \boldsymbol{\beta}\right) /\left[1+\exp \left(\boldsymbol{x}_{i}^{T} \boldsymbol{\beta}\right)\right],
$$

where $P\left(y_{i}=1 \mid \boldsymbol{x}_{i}^{T}\right)$ is the probability of success, i.e. whether the $i$-th respondent regards brands in the selected product category as important, given the observed set of explanatory variables $\boldsymbol{x}_{i}^{T}, G\left(\boldsymbol{x}_{\boldsymbol{i}}^{T} \boldsymbol{\beta}\right)$ is a simplified notation for the logistic function $\exp \left(\boldsymbol{x}_{i}^{T} \boldsymbol{\beta}\right) /\left[1+\exp \left(\boldsymbol{x}_{i}^{T} \boldsymbol{\beta}\right)\right]$. Under most practical circumstances, the maximum likelihood estimation method provides consistent and asymptotically normal estimates of the coefficients in logistic regression models (for detailed discussion, see Wooldridge 2010, p.568).

For any logistic model, the direction of the effect of change in the explanatory variable $x_{j}$ on the probability of "success" in the dependent variable is always determined by the sign of the corresponding $\beta_{j}$ coefficient. However, the magnitudes of the individual $\beta_{j}$ coefficients are not particularly informative by themselves, given the nonlinear nature of the logistic function (2). The actual 
effect of a change in $x_{\mathrm{j}}$ on the probability of "success" for the $i$-th respondent must be calculated individually: for example, let's use some binary explanatory variable, say $x_{k}$ - then, the partial effect from changing $x_{\mathrm{k}}$ from 0 to 1 (while holding all other explanatory variables unchanged) may be simply calculated as

$$
\begin{gathered}
\Delta P\left(y_{i}=1 \mid \boldsymbol{x}_{i}^{T}\right)=G\left(\beta_{0}+\beta_{1} x_{1, i}+\cdots+\beta_{k-1, i} x_{k-1, i}+\beta_{k}\right)- \\
G\left(\beta_{0}+\beta_{1} x_{1, i}+\cdots+\beta_{k-1, i} x_{k-1, i}\right),
\end{gathered}
$$

where the $G($.$) functions come from (2). In expression (3), we may note that the$ $\beta_{k}$ coefficient is present when $G($.$) is evaluated for x_{k}=1$ and omitted for $x_{k}=$ 0 . Although the population-based $\beta_{j}$ coefficients are not usually available, expression (3) may be evaluated using the sample estimates of $\beta_{j}$. As a logical next step, equation (3) may be used across all individuals in the sample, in order to conveniently summarize the estimated partial effects of changes in $x_{k}$ (or any chosen regressor). The often used average partial effect (APE) approach is based on calculating the expected partial effects of changing a given binary regressor $x_{k}$ from 0 to 1 (ceteris paribus) for each of the survey respondents and reporting the average value: $A P E\left(x_{k}\right)$. Consistent estimates of $A P E\left(x_{k}\right)$ for binary regressors may be obtained by evaluating the expression

$$
\begin{gathered}
A P E\left(x_{k}\right)=N^{-1} \sum_{i=1}^{N}\left[G\left(\hat{\beta}_{0}+\hat{\beta}_{1} x_{1, i}+\cdots+\hat{\beta}_{k-1, i} x_{k-1, i}+\hat{\beta}_{k}\right)-\right. \\
\left.G\left(\hat{\beta}_{0}+\hat{\beta}_{1} x_{1, i}+\cdots+\hat{\beta}_{k-1, i} x_{k-1, i}\right)\right],
\end{gathered}
$$

where $\hat{\beta}_{j}$ are the estimated regression coefficients and expression (4) is evaluated for all the individual observations - i.e. for all $N$ respondents. Using expression (4), APEs may be calculated for all binary regressors $x_{j}$ in our model (1). The estimated APEs may be used for interpretation and can be compared across different models (i.e. for brand loyalty in different product categories). Although all regressors in model (1) are binary, the specification chosen provides enough control for diverse observed factors that it allows for a straightforward interpretation of individual APEs - a situation that is analogous to the Ignorability of treatment assumption (see Wooldridge, 2010, p. 908). Thus, logistic regression and related methods may provide quantified results, with easily accessible and often actionable information for diverse brand management and marketing tasks. Also, the above described methodology is an extension to the quantitative analysis framework used in our previous paper (Formánek and Tahal, 2016). 


\section{RESEARCH RESULTS}

Brand perception is assessed using diverse data evaluation methods in order to quantify different aspects of brand loyalty and its consumer structure across product categories. First, the Wilcoxon signed rank tests for matched pairs (see Wackerly, Mendenhall and Scheaffer, 2008) is used to test for differences in relative frequencies of brand loyalty across product categories. For example, we may ask whether the reported percentage of brand importance (brand importance perception ratio) in the Electronics category is statistically different from other product categories. Based on our representative sample, we analyse consumer loyalty across all the selected 11 product groups. The results are summarized in Table 1, where product categories are ordered (descending order) by their perceived brand importance. The higher the product category ranks in Table 1, the more brands in a given category are associated with customer loyalty. Also, lower product category positions in the Table mean that brands have a less prominent capacity to attract customer loyalty. We test for statistically significant differences in observed means. Results of the Wilcoxon signed rank tests (matched pairs) - as performed on the 55 possible pair combinations of product groups - are visualized in the rightmost column of Table 1. The "matched pairs" version of the Wilcoxon signed rank test serves to control for specific variances in paired (correlated) observations.

The Electronics category stands out with a $45.3 \%$ positive outcome, i.e. the percentage of respondents who perceive/express brands as very important in this category. Statistically speaking, this differentiates Electronics from all other categories, where brand importance is significantly lower. At the 5\% significance level, we have identified five groups (with 2 or more elements per group) of product categories with equal brand propensity ratios (statistically speaking). For example, when the category Master domestic appliances (MDA) is pairwise compared to Shoes and to Food \& beverages, their means are not statistically different. However, when comparing the mean of Food \& beverages against Shoes, we find a nonzero difference at the $5 \%$ significance level. Therefore, the three product categories may not be combined into a single group. As shown in Table 1, two groups need to be created and the MDA category is involved in both. On the other hand, categories Restaurants, Drugstore, Household equipment and Toys form a single group as far as pairwise differences in means are concerned, as none of the mean values involved is statistically different from other group members. 
Table 1 - Propensity to brand loyalty by product categories,

Source: authors

\begin{tabular}{|c|c|c|c|c|}
\hline Product category & $\begin{array}{l}\text { Number of } \\
\text { "successes" out of } \\
490 \text { respondents }\end{array}$ & $\begin{array}{l}\text { Average } \\
\text { (positive } \\
\text { outcome } \\
\text { ratio) }\end{array}$ & Variance & $\begin{array}{c}\text { Group } \\
\text { highlighted } \\
\text { where } H_{0} \text { of } \\
\text { equal means } \\
\text { not rejected. }\end{array}$ \\
\hline Electronics & 222 & 0.453 & 0.248 & \\
\hline Shoes & 158 & 0.322 & 0.219 & \\
\hline $\begin{array}{l}\text { Master domestic } \\
\text { appliances }\end{array}$ & 151 & 0.308 & 0.214 & \\
\hline Food \& beverages & 131 & 0.267 & 0.196 & \\
\hline Clothing & 105 & 0.214 & 0.169 & \\
\hline Small domestic appliances & 103 & 0.210 & 0.166 & \\
\hline Restaurants & 77 & 0.157 & 0.133 & \\
\hline Drugstore & 71 & 0.145 & 0.124 & \\
\hline Household equipment & 67 & 0.137 & 0.118 & \\
\hline Toys & 64 & 0.131 & 0.114 & \\
\hline Hobby \& garden & 52 & 0.106 & 0.095 & \\
\hline
\end{tabular}

While interpreting the results in Table 1, we need to keep in mind the nature of the brand loyalty data: "success" is counted only if the respondent regards brands in a chosen product category as highly important. Technically, for the 4-degree Likert scale described in chapter 3 , we only discriminate between value " 1 " ("Brand in the product category is very important to me") and all other outcomes combined. This approach leads to clear differentiation between customers with sound propensity towards brand loyalty in a given product category and those without such a distinctive marketing potential. 


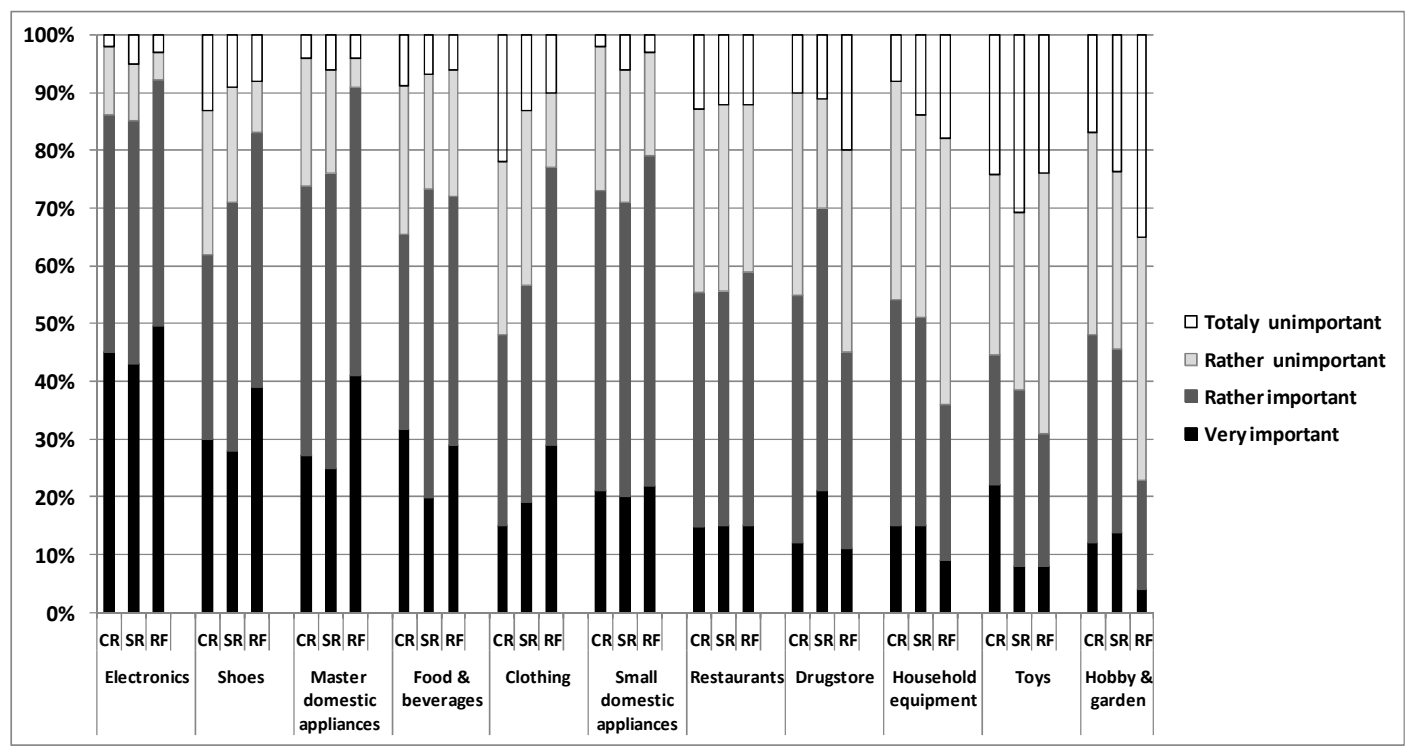

Figure 1 - The importance of product categories in the three countries, Source: Authors

Figure 1 aims to provide the readers with information on the detailed structure of the surveyed attitudes towards brand importance. In Figure 1, individual Likertscale answers are summarized across different product categories and for each of the three countries included. Hence, for each product category, there are three columns in Figure 1, displaying the differences and/or similarities among the three countries covered - CZ, SR and RF.

Using the summarized information as per Table 1 and Figure 1, we may draw conclusions about the overall potential for brand loyalty. For example, our data show that brand importance ratio in Small domestic appliances is not statistically different from the Clothing category. However, this does not mean that identical overall positive outcome ratios are generated by identical respondent groups (again, statistically speaking). In theory, positive outcomes in the two groups considered (Small domestic appliances and Clothing) may as well come from two mutually exclusive groups. In practice, many random influences play a significant role at the individual level, yet by means of logistic regression, we are able to identify and quantify many statistically significant differences in brand perception among diverse socio-demographic groups of consumers. In addition, relevant survey-based factors and indicators (such as lifestyle preferences) may be used to discern brand-related differences among respondent groups.

Next, our analysis concentrates on answering the Research Question 2. All brand loyalty data are used as dependent variables in logistic regression models in order to quantify the importance (statistical significance and magnitude) of the effects of various socio-demographic and lifestyle factors on the attitudes of respondents towards brands in different product types. Given the choice of socio-demographic and lifestyle explanatory variables described in chapter 4 , the regression model (1) was estimated for each of the 11 binary dependent variables 
describing brand importance across product categories. All the estimated logistic models are statistically significant and provide reasonable prediction accuracy. As the individual regression coefficients of the logistic models are not particularly informative - except for their signs - we skip the regression output tables and focus on the APE values from equation (4), along with their interpretation. Actually, all signs and statistical significances of the $\beta_{c, j}$ regression coefficients may be traced to their corresponding $\operatorname{APE}_{c}\left(x_{j}\right)$ values, where the subscript $c$ denotes the $c$-th product category used in equation (1). All estimation outputs omitted from this article are available from the authors upon request, along with supplementary plots, raw survey data and R-code used. In Tables 2 and 3, we report APE values calculated for each explanatory variable and every product category. The individual $A P E_{c}\left(x_{j}\right)$ values are reported along with their standard errors (heteroscedasticity-robust values are used) and pvalues. Columns in Tables 2 and 3 are organized by brand importance in the same way as rows in Table 1: the first six product categories (rows) from Table 1 are included in Table 2 and the remaining five product categories constitute Table 3. Therefore, the output allows for a simple comparison of APEs between regressors in adjacent columns, where product categories often belong to the same group in terms of the overall propensity towards brand loyalty.

For interpretation of the results shown in Tables 2 and 3, we shall use the example of Shoes and MDA categories. The information from Tables 1 to 3 may be combined as follows: Although Shoes and MDA categories do not differ in brand importance perception ratios, significant differences exist between respondent groups defined in equation (1). Brand importance perception is not determined by gender for Shoes, but women are approximately $7.9 \%$ more likely to regard brands as important in the MDA category. For Shoes, people aged 15 to 24 are $20.7 \%$ more likely to report brand importance as compared to those aged $50+$ (our reference group) and we observe $+12.5 \%$ in success probability for the age group 25-34 as compared to the reference group. In the Shoes category, age group 35-49 does not differ from the reference group in terms of reported brand importance. The age-dependence structure in Shoes may be compared to the MDA category, where people aged 25-34 and 35-49 may be associated with a $12.6 \%$ and $15.7 \%$ increases in reported brand importance, while the age group 15-24 is not statistically different from the reference. Nationality plays no role for brand perception in Shoes. For the MDA category, people from the RF are $11.7 \%$ more likely to report brands as important than the reference (CR) and consumers from SR do not exhibit distinct brand perception from the reference. While people who report being active pay card users (LS_Paycard_yes) are $11.9 \%$ more likely to report brand importance in MDA (as compared to those who report either indifferent or negative stance on the subject), this factor is not important for Shoes. Participation in touristic activities (LS_tourist_yes) leads to $+12.5 \%$ in success probability for Shoes but it plays no role for the MDA category. In contrast, gardening (LS_greenfing_yes) may be associated with $15.7 \%$ increase in brand propensity for the MDA category while it's not significant for Shoes. Respondent who strongly associate themselves with 
watching TV (LS_TV_yes) are $13.4 \%$ more likely to regard brands for Shoes as important (here, the reference group is formed by negative and neutral positions on the TV-watching subject). Low-income consumers (Earnings_low) would result in $-13.3 \%$ success probability in Shoes. For the MDA category, neither of the last two factors is significant.

In a similar way, Tables 2 and 3 may be used to identify differences and similarities in consumers' brand loyalty across any chosen product categories and/or product groups as identified in Table 1. In a stratified manner, product categories can be characterized by their potential to attract brand loyalty from consumers of different socio-demographic and lifestyle-based groups. As Tables 2 and 3 provide extensive material for comparison, readers are welcome to make own collations and conclusions. In the following paragraphs, we only focus on the most prominent, important and potentially actionable findings.

Table 2 - Estimated APEs for different product categories - columns 1-6 / 11, Source: authors

\begin{tabular}{|c|c|c|c|c|c|c|}
\hline Product categories & \multirow[t]{2}{*}{ Electronics } & \multirow[t]{2}{*}{ Shoes } & \multirow{2}{*}{$\begin{array}{l}\text { Master dom. } \\
\text { app. }\end{array}$} & \multirow{2}{*}{$\begin{array}{c}\text { Food \& } \\
\text { beverages }\end{array}$} & \multirow[t]{2}{*}{ Clothing } & \multirow{2}{*}{$\begin{array}{c}\text { Small } \\
\text { dom. app. }\end{array}$} \\
\hline Regressors & & & & & & \\
\hline \multirow{3}{*}{$\begin{array}{l}\text { Female } \\
\text { (standard error) } \\
\text { [p-value] }\end{array}$} & -0.0428 & 0.0280 & 0.0793 & 0.1252 & -0.0282 & 0.0315 \\
\hline & $(0.0455)$ & $(0.0418)$ & ( 0.0420$)$ & $(0.0397)$ & $(0.0375)$ & $(0.0363)$ \\
\hline & {$[0.3470]$} & {$[0.5039]$} & [0.0589] & [ 0.0016$]$ & {$[0.4523]$} & {$[0.3855]$} \\
\hline \multirow[t]{3}{*}{ Age_15_24 } & $0.1615^{*}$ & $0.2068 *$ & 0.0661 & 0.0379 & $0.1430 *$ & -0.0273 \\
\hline & $(0.0623)$ & $(0.0641)$ & $(0.0620)$ & $(0.0618)$ & $(0.0611)$ & $(0.0528)$ \\
\hline & [ 0.0096$]$ & {$[0.0013]$} & [ 0.2865$]$ & [ 0.5393$]$ & [0.0191] & [ 0.6044$]$ \\
\hline \multirow[t]{3}{*}{ Age_25_34 } & 0.1065 & 0.1249 & 0.1263 & 0.0113 & -0.0295 & 0.1158 \\
\hline & $(0.0640)$ & $(0.0646)$ & $(0.0646)$ & $(0.0596)$ & $(0.0562)$ & $(0.0597)$ \\
\hline & [ 0.0961$]$ & {$[0.0531]$} & [ 0.0505$]$ & [ 0.8499 ] & [ 0.5994$]$ & {$[0.0522]$} \\
\hline \multirow[t]{3}{*}{ Age_35_49 } & $0.1213^{*}$ & 0.0625 & 0.1571* & 0.0655 & -0.0141 & 0.1379* \\
\hline & $(0.0573)$ & $(0.0574)$ & $(0.0561)$ & $(0.0533)$ & $(0.0476)$ & $(0.0526)$ \\
\hline & {$[0.0344]$} & {$[0.2760]$} & [0.0051] & [ 0.2191$]$ & [ 0.7664$]$ & [ 0.0087$]$ \\
\hline \multirow[t]{3}{*}{ SR (SVK) } & -0.0462 & -0.0376 & -0.0653 & -0.1354 & 0.0642 & -0.0242 \\
\hline & $(0.0549)$ & $(0.0528)$ & $(0.0513)$ & $(0.0437)$ & $(0.0541)$ & $(0.0444)$ \\
\hline & [ 0.4002 ] & {$[0.4757]$} & [ 0.2029$]$ & {$[0.0020]$} & {$[0.2352]$} & {$[0.5864]$} \\
\hline \multirow{3}{*}{ RF (RUS) } & 0.0174 & 0.0373 & $0.1166^{*}$ & -0.0445 & $0.1438 *$ & 0.0269 \\
\hline & $(0.0547)$ & $(0.0518)$ & $(0.0519)$ & $(0.0467)$ & $(0.0516)$ & $(0.0451)$ \\
\hline & {$[0.7508]$} & {$[0.4716]$} & [0.0246 ] & [ 0.3409$]$ & {$[0.0053]$} & {$[0.5515]$} \\
\hline \multirow[t]{3}{*}{ LS_Paycard_yes } & $0.0927 *$ & 0.0599 & $0.1193 *$ & 0.0149 & 0.0346 & 0.0490 \\
\hline & $(0.0454)$ & $(0.0421)$ & $(0.0410)$ & $(0.0404)$ & $(0.0368)$ & $(0.0363)$ \\
\hline & [ 0.0414$]$ & {$[0.1556]$} & {$[0.0036]$} & {$[0.7127]$} & [ 0.3469$]$ & {$[0.1764]$} \\
\hline \multirow[t]{3}{*}{ LS_tourist_yes } & $0.0896 *$ & 0.0754 & 0.0485 & 0.0455 & 0.0495 & $0.0831 *$ \\
\hline & $(0.0448)$ & $(0.0414)$ & ( 0.0406$)$ & $(0.0395)$ & $(0.0358)$ & $(0.0355)$ \\
\hline & [ 0.0454$]$ & {$[0.0688]$} & {$[0.2323]$} & [ 0.2488$]$ & {$[0.1666]$} & {$[0.0193]$} \\
\hline \multirow{3}{*}{$\begin{array}{l}\text { LS_greenfing } \\
\text { _yes }\end{array}$} & 0.0751 & -0.0241 & 0.1573* & 0.0846 & -0.0714 & $0.1145 *$ \\
\hline & $(0.0567)$ & $(0.0547)$ & $(0.0569)$ & $(0.0547)$ & $(0.0470)$ & $(0.0538)$ \\
\hline & [0.1851] & {$[0.6598]$} & [0.0058] & {$[0.1223]$} & {$[0.1290]$} & {$[0.0335]$} \\
\hline \multirow[t]{3}{*}{ LS_TV_yes } & -0.0299 & $0.1335 *$ & -0.0451 & 0.0801 & $0.1173 *$ & -0.0047 \\
\hline & ( 0.0598$)$ & $(0.0614)$ & $(0.0562)$ & $(0.0586)$ & $(0.0593)$ & $(0.0509)$ \\
\hline & {$[0.6170]$} & {$[0.0298]$} & {$[0.4226]$} & [ 0.1718$]$ & {$[0.0479]$} & {$[0.9261]$} \\
\hline \multirow[t]{3}{*}{ Earnings_low } & $-0.1117 *$ & $-0.1326 *$ & -0.0466 & -0.0741 & $-0.0790 *$ & $-0.091 *$ \\
\hline & $(0.0524)$ & $(0.0457)$ & ( 0.0482$)$ & $(0.0449)$ & $(0.0400)$ & $(0.0394)$ \\
\hline & [ 0.0328$]$ & {$[0.0037]$} & [0.3341] & [ 0.0987$]$ & {$[0.0480]$} & [0.0209] \\
\hline
\end{tabular}

Note: $*$ - coefficient significant at $\alpha=0.05 ; \cdot$ - coefficient significant at $\alpha=0.1$. 
Table 3 - Estimated APEs for different product categories - columns 7-11/11, Source: authors

\begin{tabular}{|c|c|c|c|c|c|}
\hline \begin{tabular}{|l|}
$\begin{array}{l}\text { Product } \\
\text { categories }\end{array}$ \\
Regressors
\end{tabular} & Restaurants & Drugstore & $\begin{array}{l}\text { Household } \\
\text { equipment }\end{array}$ & Toys & $\begin{array}{c}\text { Hobby \& } \\
\text { garden }\end{array}$ \\
\hline \multirow{3}{*}{$\begin{array}{l}\text { Female } \\
\text { ( standard error) } \\
\text { [ p-value ] }\end{array}$} & & $0.0895 *$ & & 0.0447 & -0.074 \\
\hline & $(0.0326)$ & $(0.029$ & $(0.031$ & $(0.029$ & \\
\hline & {$[0.2$} & {$[0.002$} & [ 0.7855$]$ & [ 0.1228 ] & {$[0.0080]$} \\
\hline \multirow[t]{3}{*}{ Age_15_24 } & 0.0595 & 0.0341 & 0.0294 & $-0.1082 *$ & -0.0047 \\
\hline & $(0.0572)$ & $(0.0$ & $(0.0$ & $(0.0$ & $(0.0$ \\
\hline & $32]$ & {$[0.5188]$} & {$[0.5516]$} & {$[0.0005]$} & {$[0.9080]$} \\
\hline \multirow[t]{3}{*}{ Age_25_34 } & 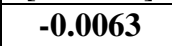 & & -0.1 & 0.13 & -0 . \\
\hline & $17)$ & ( 0.0 & ) & $(0.0$ & $(0$. \\
\hline & {$[0.9$} & {$[0.2$} & {$[0$.} & {$[0.0$} & {$[0$} \\
\hline \multirow[t]{3}{*}{ Age_35_49 } & $0.1363 *$ & $\overline{0.0}$ & 0.0 & 0.0362 & -0.0019 \\
\hline & & $(0$. & ) & ( 0.0 & ( 0.0 \\
\hline & {$[0$.} & {$[0$.} & ] & {$[0$.} & \\
\hline \multirow[t]{3}{*}{ SR (SVK) } & -0.0153 & 0.0632 & -0.0186 & $-0.1383^{*}$ & -0.0223 \\
\hline & ( 0.0401$)$ & $(0.0421)$ & $(0.0$ & $(0.0$ & ( 0.0289$)$ \\
\hline & 7] & {$[0$.} & {$[0$} & {$[0$.} & 408 ] \\
\hline \multirow[t]{3}{*}{ RF (RUS) } & $\begin{array}{l}-0.0157 \\
\end{array}$ & -0.0216 & \begin{tabular}{|c|}
-0.0388 \\
\end{tabular} & $-0.0830 *$ & -0.0530 \\
\hline & ( 0.0403$)$ & $(0.0427)$ & $(0.0370)$ & $(0.0291)$ & $(0.0299)$ \\
\hline & {$[0.6$} & {$[0$.} & {$[0$.} & {$[0.0$} & [ 0.0766 ] \\
\hline \multirow[t]{3}{*}{ LS_Paycard_yes } & 0.0386 & 0.0912* & 0.0301 & 0.0141 & $0.0580 *$ \\
\hline & ( 0.0326$)$ & $(0.0306)$ & $(0.0308)$ & $(0.0296)$ & ( 0.0288$)$ \\
\hline & {$[0.2364]$} & [ 0.0029 ] & [ 0.3283$]$ & [ 0.6322$]$ & [ 0.0438 ] \\
\hline \multirow[t]{3}{*}{ LS_tourist_yes } & -0.0043 & 0.0311 & 0.0380 & -0.0019 & -0.0141 \\
\hline & $(0.0321)$ & $(0.0304)$ & $(0.0300)$ & $(0.0282)$ & $(0.0255)$ \\
\hline & [ 0.8933$]$ & {$[0.3075]$} & {$[0.2056]$} & [ 0.9472 ] & [ 0.5805$]$ \\
\hline \multirow{3}{*}{$\begin{array}{l}\text { LS_greenfing } \\
\text { _yes }\end{array}$} & 0.0159 & 0.0598 & 0.0750 & 0.1193* & $0.2179 *$ \\
\hline & ( 0.0470$)$ & $(0.0421)$ & $(0.0452)$ & $(0.0444)$ & $(0.0502)$ \\
\hline & {$[0.7349]$} & [ 0.1560$]$ & [ 0.0966$]$ & [ 0.0073$]$ & {$[0.0000]$} \\
\hline \multirow[t]{3}{*}{ LS_TV_yes } & -0.0545 & -0.0554 & 0.0190 & -0.0084 & -0.0165 \\
\hline & ( 0.0428$)$ & $(0.0374)$ & $(0.0430)$ & $(0.0380)$ & $(0.0325)$ \\
\hline & & [0.1389] & {$[0.6581]$} & {$[0.8246]$} & [0.6109] \\
\hline \multirow[t]{3}{*}{ Earnings_low } & -0.0623 & $-0.0783 *$ & -0.0723 & -0.0157 & -0.0472 \\
\hline & $(0.0$ & ( 0.0 & $(0.0$ & $(0.0328)$ & $(0.0280)$ \\
\hline & [ 0.0803 & {$[0.0139$} & [ 0.0226$]$ & [ 0.6331$]$ & {$[0.0912]$} \\
\hline
\end{tabular}

Note: * - coefficient significant at $\alpha=0.05 ; \quad$ - coefficient significant at $\alpha=0.1$.

Gender plays no role in brand attitude for 7 of the 11 product categories, yet female respondents are more prone to brand loyalty in the MDA, Food \& Beverages and Drugstore categories by a factor of $7.9 \%$ to $12.5 \%$. In contrast, women are less likely to report brand importance in the Hobby \& garden category: $-7.5 \%$. For illustration and readers' convenience, the ceteris paribus effects on brand loyalty (along with $90 \%$ significance intervals) of the regressor Female are included in Figure 2. For example, the leftmost bar (within the Female group) shows that women are $4.3 \%$ less likely to consider brands as important in the Electronics category. At the same time, the corresponding $90 \%$ 
significance interval includes zero and thus the effect is not statistically significant at $\alpha=0.1$ (significance level of $10 \%$ ).

The most prominent age-based brand loyalty differences exist in Electronics, Shoes and MDA categories, while this factor plays no role in Food \& beverages, Drugstore, Household equipment and Hobby \& garden categories. Respondents' domicile plays a role in 5 of the 11 product categories. The most prominent geographically defined difference was observed for the Clothing category consumers in RF express $14.4 \%$ increase in potential for brand loyalty (compared to CR as a reference). Also, for the MDA category, RF is associated with $+11.7 \%$ while brands in Toys and Hobby \& garden categories are regarded as less important in RF: by $-8.3 \%$ and $-5.3 \%$ respectively. Generally speaking, brand perception is rather equal in CR and SR, with the exception of Food \& beverages (-13.5\% in SR) and Toys (- $13.8 \%$ in SR).

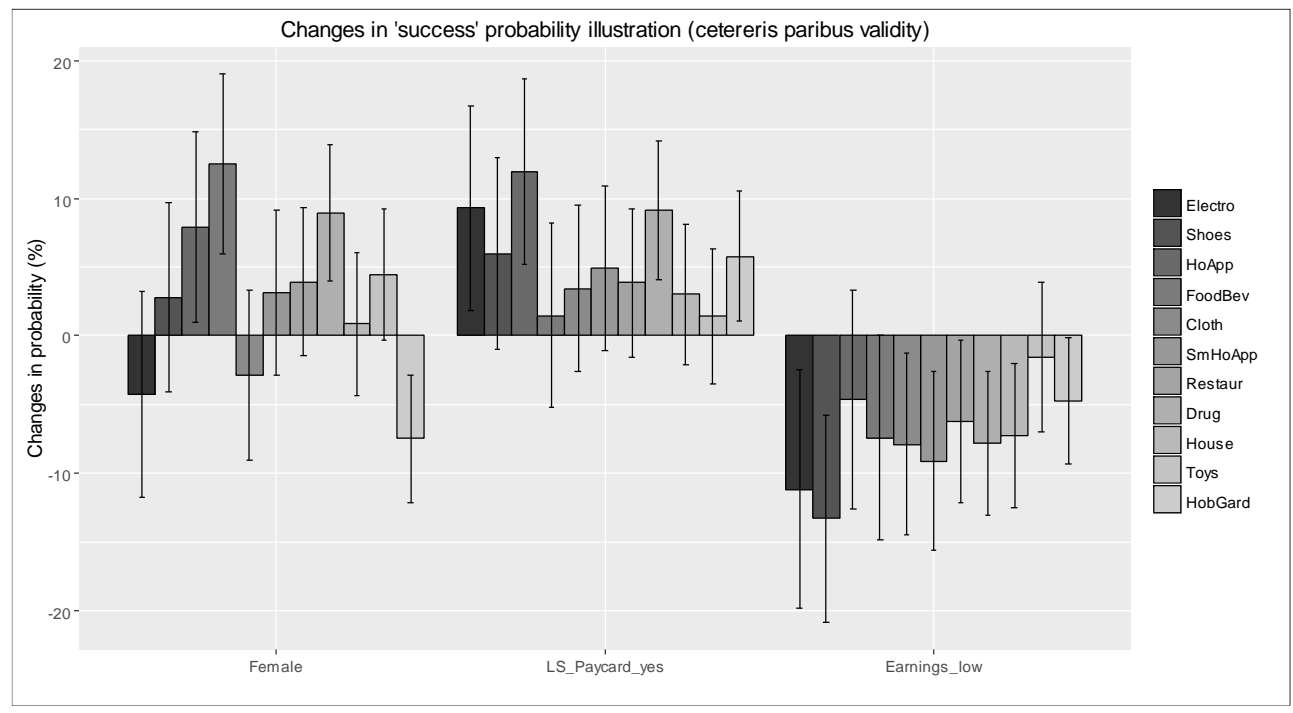

Figure 2 - Illustration of selected results from Tables $2 \& 3$ Source: authors

For the lifestyle variables, some interesting facts also may be pointed out. Respondents who associate themselves with some lifestyle or activity are more likely to attribute importance to brands in every product category considered - if statistically significant, the differences in success probabilities (compared to the reference) is always positive. The main difference between active pay card users (LS_Paycard_yes) and their reference group may be observed in the MDA category $(+11.9 \%)$, while this factor increases perceived brand importance in the Electronics and Drugstore categories by $9.2 \%$ and $9.1 \%$. Variable $L S_{-} P a y c a r d \_y e s$ is also included in Figure 2. Product categories considered, active gardeners (LS_greenfing_yes) are $21.8 \%$ more likely to attribute importance to brands in the Hobby \& garden category (a rather intuitive result), while the differences in MDA and Small domestic appliances are $+15.7 \%$ and + $11.5 \%$ respectively. 
Generally speaking, consumers with low earnings (Earnings_low) regard brands as less important. This factor is most prominent in the Shoes (- 13.3\%) and Electronics $(-11.2 \%)$ categories. For most of the remaining product categories, propensity to brand loyalty is decreased by around 7-8 \% for the lowearnings consumers. Finally, earnings have no effect on brand importance perception in the MDA and Toys categories. Illustration of the effects of low earnings on brand importance perception is also provided in Figure 2.

\section{CONCLUSIONS AND PRACTICAL IMPLICATIONS}

In this contribution, we apply a wide range of quantitative analysis tools in order to examine brand loyalty across different product categories, taking into consideration attributes that characterize consumers according to their sociodemographic classification, purchasing behaviour, attitudes towards modern technologies, work preferences, free time activities, etc. The inclusion of data gathered in three selected countries: the Czech Republic, the Slovak Republic and the Russian Federation may be viewed as a significant added value of this study as compared to previous analyses. Our study focuses on two main research topics: First, based on a statistical analysis, FMCG product categories are ranked by their power to attract customers' interest for brands in each of the categories. Second, based on the logistic regression and related analyses (average partial effects), variables representing socio-demographic and lifestyle factors that most distinctly characterize the consumer groups exhibiting significant positive or negative propensity towards brand loyalty are highlighted and interpreted.

Considering the results shown in previous studies and the results shown here, we are convinced about the usefulness of applied quantitative research in the field of customer loyalty as an integral part of marketing science. For example, when building up effective loyalty programs, it is important to discern brands where loyalty is predetermined by the very product category from product categories where the brand choice is unstable and where focused marketing activities are desirable.

This paper also emphasizes the fact that brand loyalty is a highly complex phenomenon and that it can and should be analysed from different points of view. Our research can help marketers to find out whether their brands belong to a product category with an inherent tendency to give rise to positive emotions and to attract customers, or whether spontaneous bonds in the category are weak and it is therefore meaningful to support customer loyalty by investing time and money into suitable loyalty programs. Our research also shows that the segmentation based on sociodemographic and life-style factors would be very useful for customization of loyalty programs - we find significant differences in brand attitudes between specific customer groups across product categories. 


\section{ACKNOWLEDGMENT}

This article was processed with contribution of the long term institutional support of research activities by Faculty of Informatics and Statistics, University of Economics, Prague.

\section{REFERENCES}

Bennett, R., 2001. A study of brand loyalty in the business-to-business services sector. Ph. D. The University of Queensland.

Buckinx, W. and Van den Poel, D., 2005. Customer base analysis: partial defection of behaviourally loyal clients in a non-contractual FMCG retail setting. European Journal of Operational Research, 164(1), pp.252-268.

Chaudhuri, A. and Holbrook, M.B., 2001. The chain of effects from brand trust and brand affect to brand performance: the role of brand loyalty. Journal of marketing, 65(2), pp.81-93.

Chung, C.W. and Hsu, J.J., 2012. Application of Life Style Model to Analyze the Market of Department Stores. Journal of Service Science and Management, 5(3), pp.302-311.

Cunningham, R.M., 1956. Brand loyalty-what, where, how much. Harvard Business Review, 34(1), pp.116-128.

Formánek, T. and Tahal, R., 2016. Brand importance across product categories in the Czech Republic. Management \& Marketing, 11(1), pp.341-354.

Fullerton, G., 2005. The impact of brand commitment on loyalty to retail service brands. Canadian Journal of Administrative Sciences/Revue Canadienne des Sciences de l'Administration, 22(2), pp.97-110.

García Gómez, B., Gutiérrez Arranz, A. and Gutiérrez Cillán, J., 2006. The role of loyalty programs in behavioral and affective loyalty. Journal of Consumer Marketing, 23(7), pp.387-396.

Garland, R. and Varey, R., 2006. Loyalty or profitability: banks are wising up to ways of segmenting their customers that may spell the end for long-term relationships. [pdf] Marketing Magazine, [online]. Available at: <http://www.ianbrooks.com/useful-ideas/articles_whitepapers/loyalty-orprofitability.pdf> [accessed January 10, 2016].

Grayson, K. and Ambler, T., 1999. The dark side of long-term relationships in marketing services. Journal of Marketing Research, 36(1), pp.132-141.

Ghose, S. and Lowengart, O., 2013. Consumer choice and preference for brand categories. Journal of Marketing Analytics, 1(1), pp.3-17.

Guest, L., 1944. A study of brand loyalty. Journal of Applied Psychology, 28(1), p.16. 
Huy Tuu, H. and Ottar Olsen, S., 2013. Consideration set size, variety seeking and the satisfaction-repurchase loyalty relationship at a product category level. Asia Pacific Journal of Marketing and Logistics, 25(4), pp.590-613.

Hur, W.M., Ahn, K.H. and Kim, M., 2011. Building brand loyalty through managing brand community commitment. Management Decision, 49(7), pp.1194-1213.

James, G., Witten, D., Hastie, T. and Tibshirani, R., 2013. An Introduction to Statistical Learning with applications in $R$, New York. [online]. Available at: http://www-bcf.usc.edu/ gareth/ISL/ [accessed December 19, 2015].

Lau, G.T. and Lee, S.H., 1999. Consumers' trust in a brand and the link to brand loyalty. Journal of Market-Focused Management, 4(4), pp.341-370.

McMullan, R. and Gilmore, A., 2008. Customer loyalty: an empirical study. European Journal of Marketing, 42(9/10), pp.1084-1094.

Meyer-Waarden, L., 2007. The effects of loyalty programs on customer lifetime duration and share of wallet. Journal of Retailing, 83(2), pp.223-236.

Oliver, R.L., 1999. Whence consumer loyalty? The Journal of Marketing, 63(Fundamental Issues and Directions for Marketing), pp.33-44.

Rundle-Thiele, S., 2005. Exploring loyal qualities: assessing survey-based loyalty measures. Journal of Services Marketing, 19(7), pp.492-500.

Sambandam, R. and Lord, K.R., 1995. Switching behavior in automobile markets: a consideration-sets model. Journal of the Academy of Marketing Science, 23(1), pp.57-65.

SAS, 2014. Customer loyalty managers: Build affinity first; customer retention will follow, [online]: <http://www.sas.com/en_us/news/pressreleases/2014/september/customer-intelligence-iia.html >, [accessed January 11, 2016]

Tahal, R. and Stříteský, V., 2014. Věrnostní programy a jejich vnímání zákazníky a provozovateli retailových internetových obchodů [Loyalty Programs and their Perception by Customers and by the Operators of Retail E-shops]. Acta Oeconomica Pragensia. 22(4), pp.30-41.

Wackerly, D., Mendenhall, W. and Scheaffer, R.L., 2008. Mathematical Statistics with Applications, 7th edition. Duxbury Press, CA., pp.777-782.

Wooldridge, J.M., 2010. Econometric Analysis of Cross Section and Panel Data, 2nd edition., Cambridge, Massachusetts: MIT Press.

Zablah, A.R., Brown, B.P. and Donthu, N., 2010. The relative importance of brands in modified rebuy purchase situations. International Journal of Research in Marketing, 27(3), pp.248-260. 


\section{ABOUT THE AUTHORS}

Mgr. Radek Tahal, Ph.D., assistant professor at the Faculty of Business Administration, University of Economics, Prague, Czech Republic. He specialises in market research, particularly consumer loyalty. e-mail: radek.tahal@vse.cz

Ing. Tomáš Formánek, Ph.D., assistant professor at the Faculty of Informatics and Statistics, University of Economics, Prague, Czech Republic. His research focuses around econometrics and related statistical methods, with microeconomic and macroeconomic applications. e-mail: formanek@vse.cz 